\title{
Modesto Armijo Lozano. Diario dedicado a su esposa, Carmenza Mejía Aráuz
} (octubre 1926- julio 19279), Mónica Toussaint

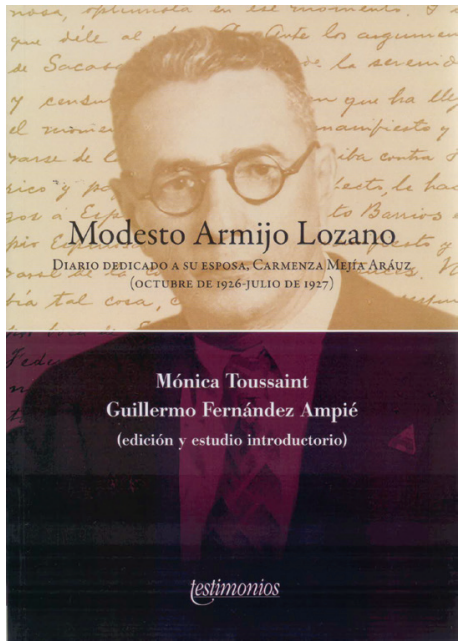

y Guillermo Fernández Ampié (Edición y estudio introductorio), Instituto José María Luis Mora, México, 2015, 4I Ipp.

Alejandra G. Galicia Martínez xtabayam@yahoo.com.mx

se puede comprender el inicio de la defensa del gobierno constitucional de Sacasa, las intervenciones de los distintos actores
Como parte de abonar al estudio de la historia de Centroamérica la doctora Monica Toussaint y el doctor Guillermo Fernández Ampié editaron: Modesto Armijo Lozano, Diario dedicado a su esposa, Carmenza Mejía Aráuz (octubre 1926- julio 19279).Incluido en la colección Testimonios del Instituto Mora. El texto publicado en 2015 puede considerarse una valiosa fuente histórica para analizar la Guerra Constitucionalista nicaragüense (1926-1927) que involucró a los países centroamericanos, Estados Unidos y México.

Si bien Modesto Armijo, quien fue partedelgabinetedegobierno deJuan Bautista Sacasa durante la Guerra Constitucionalista, es un personaje poco conocido dentro de la historiografía nicaragüense y centroamericana. La publicación de su Diario es una muestra de que aún a inicios del siglo XXI existen episodios y procesos históricos que no terminan de revisarse, y queda mucho por analizar y develar.

Uno de estos procesos históricos es el que tiene que ver con los vínculos entre México y Nicaragua, en ese contexto de los años veinte del siglo pasado y de los cuales es resultado la publicación de las notas de Armijo. Es a partir de esta información que dentro del conflicto, así como su desenlace, considerado el escenario que da pie a la emergencia del movimiento armado liderado por Augusto C. Sandino.

Un texto de esta índole, en el que se desbordan datos de personajes, tiempos y espacios difícilmente podría entenderse sin una contextualización. Es por ello que los editores, especialistas en historia política y diplomática entre Centroamérica y México, incluyen un estudio introductorio que ubica temporalmente al Diario tomando en cuenta los distintos temas que podemos encontrar en los apuntes de Armijo. Ellos desglosan los antecedentes de la Guerra Constitucionalista partiendo del escenario regional que involucra los intereses geopolíticos de Estados Unidos en Centroamérica y las tensiones políticas entre los gobiernos de Estados Unidos y México a inicios del siglo XX.

Dentro de este contexto, explicado por los editores, se encuentran los acontecimientos que definieron la ocupación norteamericana de 1912 a 1927: la renuncia del caudillo liberal José Santos Zelaya y su legado en materia de derechos civiles para Nicaragua y la subsecuente ocupación estadounidense entre 1910 y 1912; la firma 
del Tratado Chamorro-Bryan de 1914, los distintos intentos de restablecimiento de la unificación centroamericana entre 1921 y 1923; el arribo de la dupla Solorzano -Sacasa a la presidencia de Nicaragua en 1924 y el golpe de Estado de Emiliano Chamorro, conocido como "El Lomazo" en 1925.

El estudio introductorio además de describir los antecedentes de la Guerra Constitucionalista, sitúa a los actores involucrados en el conflicto político en todos sus niveles, tanto en el ámbito interno como en el regional en el que se involucran los gobiernos e intereses de los países centroamericanos, México y los Estados Unidos. Además, el estudio presenta un cronograma que permite reconstruir las interacciones políticas entre los actores, e incluye un par de mapas que ayudan al lector a seguir geográficamente los hechos que va reconstruyendo Armijo en su Diario.

A la muerte del conservador Diego Manuel Chamorro, presidente de Nicaragua entre 1921 y 1923, la formula compuesta por Carlos Solórzano (conservador) y Juan Bautista Sacasa (liberal), conocido como gobierno de la "Transacción" asumió la presidencia y vicepresidencia en 1924. Este gobierno facilitó el retiro de las tropas norteamericanas de territorio nicaragüense al siguiente año e inmediatamente se produce el golpe de Estado encabezado por Emiliano Chamorro, conocido como el Lomazo.

La coyuntura de la ruptura constitucional tras el golpe de estado, no estaba en los cálculos de los Estados Unidos que mantenía una política injerencista en Centroamérica y el Caribe, poniendo a prueba los acuerdos de Washington firmados en 1923 donde se establecía que no se reconocería ningún gobierno emanado de un golpe de Estado. Frente a este panorama, el grupo de liberales encabezado por Sacasa emprendió la defensa del orden constitucional lo que implicó la condena del gobierno de Emiliano Chamorro, la búsqueda de reconocimiento del gobierno norteamericano. Este hecho propició el regreso inmediato de las tropas estadounidenses a Nicaragua.
Este es el escenario en el que se inscriben las notas de Modesto Armijo. En ellas podemos encontrar la visión de un hombre comprometido con la causa liberal, las impresiones sobre los principales actores que intervinieron en el conflicto, así como su sentir en los 14 meses que formó parte del gobierno constitucional de Sacasa.

El texto está dividido en dos partes. La primera abarca de octubre a diciembre de 1926, meses en los que el grupo de liberales deciden defender el orden constitucional conformando un gabinete de gobierno presidido por Sacasa en Guatemala. Describe además la negativa de Estados Unidos por reconocer este gobierno en el exilio, el desconocimiento del gobierno de Chamorro y el apoyo a Adolfo Díaz como presidente de Nicaragua.

Armijo describe el itinerario, en esta primera parte, que siguieron los liberales, desde su llegada a Guatemala y su paso por El Salvador, lugares donde Sacasa y su gabinete se posicionan políticamente, toman decisiones y se comunican con el exterior, denunciando primero el golpe de Estado y después la ocupación de Nicaragua por parte de Estados Unidos. Detalla el apoyo militar y diplomático que obtuvieron los liberales nicaragüenses del gobierno mexicano encabezado por Plutarco Elías Calles para realizar las expediciones armadas a Corinto y Puerto Cabezas, bajo el argumento de la defensa del orden constitucional. Acción que se verá frustrada cuando los norteamericanos declaran Puerto Cabezas como zona neutral.

La segunda parte abarca de enero a julio de 1927, período en el que Sacasa y su gabinete están instalados y controlados por la marinería norteamericana en Puerto Cabezas. Armijo narra los dos flancos de resistencia de los liberales nicaragüenses: la diplomática y la armada. La resistencia diplomática consiste en las constantes negociaciones entre los liberales y las autoridades norteamericanas para solucionar el conflicto, así como los trabajos diplomáticos de Timoteo Vaca Seydel, José Pedro Zepeda y Clodomiro 
Urcuyo en Estados Unidos, México y Costa Rica respectivamente.

La resistencia armada por su parte, encabezada por José María Moncada en Nicaragua es descrita como una empresa precaria pero sostenida a toda costa con recursos que llegaban del exterior y de los pocos recursos con que se contaba en el interior. La precariedad es una de las características, según las notas de Armijo, que describe al gobierno constitucional. Este segundo momento se centra en las distintas propuestas hechas por nicaragüenses, estadounidenses y centroamericanos para poner fin al conflicto político. El texto finaliza con la desarticulación del gobierno de Sacasa tras la confirmación de la noticia de la firma del acuerdo de paz entre Henry L. Stimpson y José María Moncada sin previa consulta al gobierno constitucional, y la salida del grupo de liberales de Puerto Cabezas hacia Costa Rica, primero, y Guatemala después, en junio y julio de 1927.

Como fuente primaria el Diario arroja una valiosa información para el análisis de la Guerra Constitucionalista desde varias dimensiones. Nos centraremos en cuatro de esta dimensiones, que consideramos son los ejes de las memorias de Armijo y que reflejan la complejidad y continuidad de la presencia norteamericana en Nicaragua durante las primeras tres décadas del siglo XX.

La primera de ellas, la dimensión diplomática. La historiografía que trata la intervención norteamericana de 1926 se caracteriza por poner énfasis en la presencia norteamericana como un como un acto de fuerza, sin embargo, el texto de Armijo da luces de los matices de esta afirmación. Al describir la forma en que se van involucrado los intereses de los distintos países centroamericanos, mexicano y norteamericano frente al conflicto nicaragüense, el ministro de educación muestra la existencia de una fluida comunicación entre el gobierno de Juan Bautista Sacasa, el estadounidense y el Congreso de este último país.
Esta comunicación con los norteamericanos, no implicó que Sacasa cediera a las peticiones de los gobernantes del norte, al contrario evidencia la destacada labor que hacían Vaca Seydel y Zepeda desde Estados Unidos y México para defender el orden constitucional de Nicaragua. El trabajo diplomático de estos personajes no se agotaba en la negociación y búsqueda de apoyo político, implicaba también la difusión de información a favor de la resistencia liberal, saliéndole al paso a la información tendenciosa o equivocada, que salía de los corrillos políticos norteamericanos contra el gobierno de Sacasa.

Los matices temáticos de las negociaciones entre Sacasa y Estados Unidos se fundamentaron en la necesidad de encontrar puntos de encuentro para el reconocimiento de la constitucionalidad nicaragüense. Esta situación se vio reflejada en 1926 con la conformación del gabinete del gobierno constitucional (en el exilio), configurado con personajes liberales que consideraban serían del agrado del Departamento de Estado.

Un episodio similar al arriba descrito se registró en abril de 1927 cuando Henry L. Stimson, representante del gobierno estadounidense, entregó a Sacasa un documento para la firma de la paz, donde se explicitaban condiciones como la integración de liberales en el gobierno de Adolfo Díaz, la "super vigilancia" de las elecciones de 1928 y la presencia de los marinos norteamericanos con garantes de cada una de las disposiciones. A pesar de que este documento contrastaba con la actitud demostrada por los liberales nicaragüenses, después de 12 meses de conflicto y con un gabinete desgastado, el documento fue sometido a discusión al interior del grupo que encabezaba Sacasa donde se sugiere intensiones de ser aceptado.

En el terreno diplomático los liberales nicaragüenses contaban con el apoyo de los legisladores norteamericanos, entre los destacados estaban los senadores William Borah, King Reed, Shipstead y Norris quienes eran fuertes críticos de la 
política expansionista norteamericana en la Cuenca del Caribe y Centroamérica durante el periodo de 1912 a 1930. Aunque el apoyo diplomático era relevante no fue suficiente para la resistencia nicaragüense. De ahí la importancia de la ayuda que consiguieron en México. El gobierno de Plutarco Elías Calles fue pieza clave en términos diplomáticos y militares, entre noviembre y diciembre de 1926.

Armijo devela la ayuda mexicana en su nota del 9 de diciembre:

Don Clodomiro Urcuyo, nuestro representante en Costa Rica, comunica que el gobierno de México ha reconocido al Dr. Sacasa. Esta noticia que todos esperábamos es tan grata como la de la llegada de 1000 rifles y municiones en la goleta Superior, hace pocos días. Por supuesto que la ojeriza yanqui para con nosotros viene a aumentarse. Sin el apoyo de México ni siquiera hubiéramos iniciado el movimiento, pero ese mismo apoyo nos coloca en peor posición ante el bucanero rubio. (pág. 101)

La relevancia del gobierno mexicano en el conflicto entre Nicaragua y Estados Unidos también implicaba el consejo de cómo manejarlo. Este elemento era considerado como una cortesía o deferencia de parte del gobierno de Sacasa, de manera particular por el apoyo brindado, que implicaba también mantener el secreto entre ambas partes.

En otro orden, la ayuda conseguida en Centroamérica fue relevante porque fortaleció el proyecto unionista. Si bien el trabajo de los representantes del gobierno de Sacasa fue de gran significación, especialmente en Costa Rica, es importante destacar el sostén material y moral de políticos e intelectuales centroamericanos que contribuyeron a la organización y difusión de información a favor del gobierno instalado en Puerto Cabezas (Bilwi), a partir de criterios fundamentados en la importancia del proyecto de unificación de los países centroamericanos. Sin embargo, a pesar de las diferentes manifestaciones, Armijo acertadamente intuye solo las buenas intenciones, pues durante los meses del gobierno de Sacasa nunca se materializaron.

Durante la narración de Armijo se puede apreciar que la sincronización entre el apoyo diplomático y el militar eran necesarios para los liberales, pues frente a la desventaja económica y política con la que operaban, tuvieron que echar mano de otro tipo de recursos como los medios de comunicación. El papel de estos en este conflicto, corresponde a la segunda dimensión a resaltar. La importancia de los diarios, el cable y el cine no solo tenían intención de establecer una comunicación con el resto del continente para establecer los posicionamientos políticos requeridos, sino que eran los mecanismos de producción de información, además creaba opinión pública.

La prensa norteamericana, como The New York Times, The World, The Baltimore Sun, The Chicago Tribune, fue fundamental para los liberales nicaragüenses, pues a partir de ella se enteraban de cómo se configuraba el escenario político y militar norteamericano y sopesaban el rumbo de su resistencia. La cercanía de los periodistas norteamericanos a Sacasa y su gabinete estuvo a la orden del día durante su estancia en Puerto Cabezas, incluso éstos eran fuente de información fundamental, pues confirmaban o desmentían las noticias que obtenían sobre los movimientos de los marines norteamericanos y sus combates con las tropas liberales. Según Armijo, fue un periodista norteamericano el que confirmó la noticia de la firma de la paz entre Stimpson y Moncada.

Las comunicaciones por cable también fueron fundamentales, incluso Armijo asegura: "Si no fuera por la comunicación radiográfica, el mundo no se daría cuenta de nuestra existencia" (Pág. 152). El uso de los medios de comunicación por parte de los liberales nicaragüenses auxilió a sostener, desde el punto de vista anímico, la resistencia. Se recibían noticias como la siguiente: 
El servicio radiográfico de los vapores yanquis frente a este puerto nos suministra dos noticias importantes: el aumento del distanciamiento entre el ejecutivo norteamericano y el Senado con motivo de los asuntos de Nicaragua y México, y la cancelación que ha hecho el General Calles del permiso de explotar cinco pozos de petróleo pertenecientes a los yanquis [...] Nuestra causa vive todavía gracias, digámoslo con franqueza, al gesto de dignidad que hace el pueblo norteamericano. (Pág. 154)

No solo el cablegrama fue una herramienta utilizada por los liberales y todo lo que circulaba por este medio, sino que también la Casa Pathé, compañía cinematográfica francesa, envió a un representante a seguir los movimientos de Sacasa y su gabinete. Los noticieros de esta importante casa del entretenimiento, utilizó información de los sucesos de Nicaragua en sus primeros noticieros.

La tercera dimensión a resaltar tiene que ver con las contradicciones al interior del grupo de liberales nicaragüenses. Buena parte de las descripciones que hace Armijo se centran en las desavenencias entre los personajes que rodeaban a Sacasa. Las primeras resistencias se manifestaron en 1926 con la conformación del propio gabinete. Las discusiones más importantes se dieron en torno a la recaudación y gasto de los pocos recursos que obtenían para sostener la resistencia armada.

Dos elementos fundamentales surgidos de las contradicciones existentes, explican el desenlace final de este episodio de la resistencia liberal en 1927. El primero se relaciona con el grado de confianza y autonomía adquirido por el General José María Moncada, como figura destacada dentro del liberalismo, tanto dentro del gobierno de Sacasa como en el campo de batalla, dirigiendo las tropas liberales. Según la información que se desprende del Diario, existían antecedentes de la postura de Moncada frente a las negociaciones con
Estados Unidos. En una nota periodística fechada en marzo de 1927, un periodista comenta:

Encargóme enviarle sus recuerdos. Moncada díjome que aunque no podía expresarse oficialmente, puesto que no es más que militar a las órdenes de usted, él deseoso de paz por interés Nicaragua [sic] que está ahora en estado de anarquía, aprobaría personalmente que Estados Unidos se hiciera cargo del gobierno garantizando elecciones libres 1928, garantizando amnistía para los soldados liberales y pago gastos de guerra. (Pág.249) (Cursivas del texto)

De tal manera que las noticias recibidas en mayo sobre las condiciones del acuerdo de paz (conocido como Pacto del espino negro) negociado por Moncada, tenía su antecedente. Esto no disminuye el impacto que causó en el gabinete de Sacasa la forma unilateral (artera) con que este personaje aceptaba las condiciones de paz, que ellos habían discutido y rechazado en abril.

El tratado de paz contemplaba que Moncada deponía las armas, garantizaba la continuidad del gobierno de Adolfo Díaz, avalaba la creación de una Guardia Nacional bajo la tutela estadounidense. En adición, aceptaba la súper vigilancia de las elecciones de 1928 y la presencia de los marines norteamericanos hasta esa fecha. Con ello allanaba el camino para su candidatura presidencial.

El segundo elemento está relacionado con el liderazgo de Juan Bautista Sacasa. Uno de los principales conflictos entre los liberales fue la ambivalencia que mostraba Sacasa en temas delicados. Según Armijo existieron conflictos de intereses con las designaciones de cargos que Sacasa concedió a sus parientes cercanos, hasta el punto de convertirse en escándalo dentro de la cúpula liberal. Pero este hecho no tuvo la transcendencia que sí tuvo en todo este período, la toma de decisiones unilateral, sin consultar al resto de miembros. Esta actitud 
irritó a buena parte de su gabinete, pues muchos de ellos externaban que únicamente se llamaba para asumir responsabilidades sin discutirlas ni consensuarlas.

La alta estima que Armijo le profesaba a Sacasa a mediados de 1926, calificándolo de "alma pura", con un "excesivo respeto a las personas" y un "patriota", al siguiente año, se desvanece al calificarlo como una persona voluble o irresoluta. Aun percibiendo este contraste en el carácter del dirigente liberal, permanecería leal a la empresa política y cercano al presidente Constitucional hasta el último momento.

Este cúmulo de situaciones observada durante la lectura del Diario retrata el estado de ánimo prevaleciente en Armijo y resto de liberales frente al conflicto político y las luchas que ellos libran. Durante buena parte de los 14 meses que duró la resistencia liberal, donde se nota esperanzas, desencuentros, optimismo y decepción, el ministro de educación mantendrá su pronóstico de la derrota del gobierno del que formaba parte.

La última dimensión que se quiere resaltar, es la retórica patriótica que en ocasiones desborda el texto de Armijo. Además de la forma de expresarse fundamentando la defensa de su terruño, se siente una fe profunda por el Unionismo centroamericano y latino americanismo.

Las figuras retóricas utilizadas por Armijo están más próximas a la escritura del modernismo centroamericano, caracterizado por un estilo formalista y cargado de simbolismo. Los giros con gran sonoridad, la combinación de rimas y metáforas recuerdan la elegancia de la escritura modernista.

Dentro de este despliegue modernista se aprecian formas de describir al enemigo que se coincidentemente se encontrarán en algunos escritos de Augusto C. Sandino durante la primera etapa de su levantamiento armado:

Triste con la aplastante tristeza de las noches polares, y preñada de peligros si llegara el momento en que los banqueros de Wall Street triunfaran sobre la opinión del universo. De todo son capaces los sabuesos del imperialismo yanqui; hasta de entregarnos atados de pies y manos a la ferocidad de los traidores. ¿No entregaron acaso la crueldad de los filipinos, a los españoles que en 1898 se rindieron ante las hordas de DeWet, confiados en la caballerosidad que debe caracterizar a un hombre civilizado? Tan "mantecosos" o más que los españoles, somos nosotros para estos rubios sin honor y sin conciencia [...] (Pág. 191)

Para finalizar, es bueno decir que el autor de estas memorias define el sentido de la resistencia como una problemática nacional inmerso en un contexto internacional. La referencia al patriotismo y la dignidad de la nación nicaragüense, de denuncia al imperialismo yanqui, apelando a la fraternidad continental es una muestra de ello. Esta postura, de alguna manera se observará con mayor fuerza en la resistencia liderada por el líder guerrillero Augusto C. Sandino entre 1927 y 1933.

Varias son las dimensiones desde el cual se puede abordar el Diario de Armijo, y esta reseña no pretende agotarla. Sin embargo, no quiero dejar de remarcar la importancia de la publicación de un documento como éste, poniendo en perspectiva el pensamiento de un personaje, quizás poco conocido, pero relevante dentro de la historia intelectual nicaragüense.

De igual manera, la publicación de este texto evidencia que los procesos históricos, por muy estudiados que se encuentren, nunca se dan por concluidos. Siguen apareciendo documentos y perspectivas de análisis novedosas, que como este documento inédito hasta hace poco, vienen a reelaborar las lecturas de la historia de México y Centroamérica. 